\title{
SPECIA \\ Legal Considerations in a Nuclear Detonation
}

\author{
Susan E. Sherman, JD, MHS
}

\section{ABSTRACT}

This article summarizes public health legal issues that need to be considered in preparing for and responding to nuclear detonation. Laws at the federal, state, territorial, local, tribal, and community levels can have a significant impact on the response to an emergency involving a nuclear detonation and the allocation of scarce resources for affected populations. An understanding of the breadth of these laws, the application of federal, state, and local law, and how each may change in an emergency, is critical to an effective response. Laws can vary from 1 geographic area to the next and may vary in an emergency, affording waivers or other extraordinary actions under federal, state, or local emergency powers. Public health legal requirements that are commonly of concern and should be examined for flexibility, reciprocity, and emergency exceptions include liability protections for providers; licensing and credentialing of providers; consent and privacy protections for patients; occupational safety and employment protections for providers; procedures for obtaining and distributing medical countermeasures and supplies; property use, condemnation, and protection; restrictions on movement of individuals in an emergency area; law enforcement; and reimbursement for care.

(Disaster Med Public Health Preparedness. 2011;5:S65-S72)

Key Words: legal protections, liability, emergency declarations, nuclear detonation

A n emergency involving an attack with a nuclear device raises public health legal issues at the federal, state, territorial, local, tribal, and community levels. Federal, state, and local public health and emergency laws can have a significant impact on the response to public health emergencies and the allocation of scarce resources for affected populations. An understanding of the breadth of these laws, the application of federal, state, and local laws, and how each may change in an emergency is critical to an effective response.

Federal public health law is based in the US Constitution, federal statutes, and regulations. ${ }^{1}$ State law is derived from inherent police powers to protect the public, and may also be expressed in state constitutions, statutes, and regulations. ${ }^{1}$ Local governments have public health authorities bestowed by the state under "home rule" statutes, which they may implement through regulations or local ordinances. ${ }^{2}$ Declarations of emergency, with varying effects, may be issued at the federal, state, and local levels. ${ }^{3,4}$ Any of these declarations would be likely after a nuclear detonation. Declarations issued by the federal government and some state and local jurisdictions can be somewhat limited in effect, specifying emergency actions that are legally authorized, or legal requirements that may be waived or modified after the declaration. ${ }^{5-7}$ Other states and local jurisdictions may issue declarations that permit a broad waiver or modification of any state or local laws as needed to respond to the emergency. ${ }^{5}$ In addition, at all levels, laws and regulations governing nonemergency activities may contain provisions for waivers, exceptions, or modifications to legal requirements in an emergency, with or without a formal federal, state, or local declaration of an emergency. ${ }^{8}$

This article highlights legal issues that may need to be considered in responding to a nuclear detonation involving mass casualties and requiring resources from multiple jurisdictions. It is a summary of issues to be considered, and is not legal advice or advocacy for any particular laws or approaches to be adopted by a jurisdiction. In general, the relevant legal authorities apply to any public health emergency, and are not specific to a nuclear detonation. The article highlights how these general laws may apply in an emergency involving a nuclear detonation and laws that have specific requirements relating to an emergency involving a nuclear detonation. The topics of discussion include legal issues that may be raised regarding liability protections for responders handling mass casualties with scarce resources applying different standards of care; meeting licensing, credentialing, and scope of practice requirements in such a situation; respecting patients' legal protections; responder safety; availability of supplies and facilities; and reimbursement. All of these legal issues are likely to arise in a response to an emergency involving an attack with a nuclear device.

Because many of the relevant legal authorities vary from state to state, emergency responders and health care providers should consult with their state and local lawyers regarding each of these issues to determine what specific legal authorities and requirements apply in their jurisdiction. Authorities should be examined for reciprocity and flexibility both within the responding ju- 
risdiction, and across multiple jurisdictions as responders may cross state lines or modify health care practices to respond to a nuclear detonation. ${ }^{9}$ To assist in identifying the key legal issues, the Table is a checklist of legal considerations in a nuclear detonation.

\section{LEGAL ISSUES TO BE CONSIDERED Liability of Health Care Providers}

Liability protection is 1 of the primary concerns raised when responders consider the prospect of handling mass casualties with limited resources, as is likely to occur in an emergency following a nuclear detonation. ${ }^{10,11} \mathrm{~A}$ variety of protections may be in place at the federal, state, and local levels.

A fundamental concept in determining liability is standard of care. Health care providers have raised concerns about the potential for increased liability and the corresponding risk of malpractice or negligence claims or even criminal allegations when scarce resources may have to be allocated and the normal standards of care cannot be sustained..$^{12}$ In an austere setting, such as after a nuclear detonation, standards of care that are different from those used in day-to-day practice may need to be used in the field, in alternate care facilities, and in formal health care settings. Responders outside the immediate area may also experience a strain on resources and use different standards of care when receiving injured patients, particularly if providers have been deployed to the emergency area.
The term standard of care is used in both medical and legal settings. The medical standard of care is based largely on professional requirements and norms established by professional societies, government agencies, accrediting organizations and other entities, and varies among types of health care facilities. The medical standards of care can fluctuate in emergencies to allow for rapid changes in practices as circumstances evolve. ${ }^{12}$ As a general rule, the legal standard of care is a flexible concept defined at the state level by state legislatures or judicial decisions, and is based on what a reasonable practitioner would do under similar circumstances. ${ }^{12}$ A court may look at professional standards and norms, as well as the circumstances facing the provider. Thus, the legal standard of care can take into account the emergency conditions facing the provider, acknowledging that a reasonable provider may not be able to use normal standards of care in an emergency, and look to the medical standards that a reasonable provider would follow in those conditions. ${ }^{10}$ State and local courts may compare what practitioners of the same specialty would do at the national level or what practitioners would do in the same or a similar local area. ${ }^{12}$ States, tribes, and local governments may also choose to establish crisis standards of care. ${ }^{13}$ This concept is still being explored. ${ }^{14-16}$ Crisis standards of care are described as taking into account both medical and legal standards of care, as well as other factors. ${ }^{13}$ Courts could choose to take these crisis standards of care protocols into account when determining whether a provider took the same actions that a reasonable practitioner would take un-

\section{TABLE}

\section{Legal Considerations in a Nuclear Detonation: A Checklist}

Federal declarations

State declarations

Laws protecting the population, patients, and responders

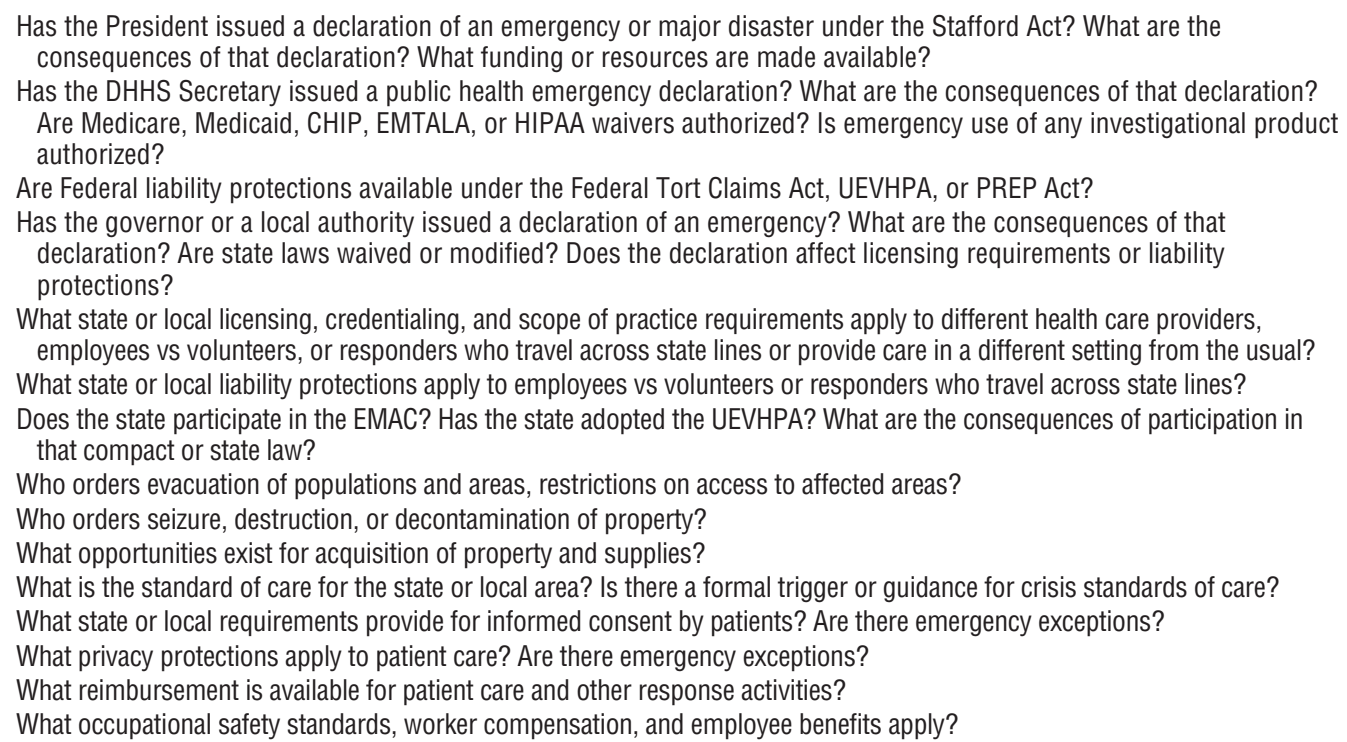

Has the President issued a declaration of an emergency or major disaster under the Stafford Act? What are the consequences of that declaration? What funding or resources are made available?

Has the DHHS Secretary issued a public health emergency declaration? What are the consequences of that declaration? Are Medicare, Medicaid, CHIP, EMTALA, or HIPAA waivers authorized? Is emergency use of any investigational product authorized?

Are Federal liability protections available under the Federal Tort Claims Act, UEVHPA, or PREP Act?

Has the governor or a local authority issued a declaration of an emergency? What are the consequences of that declaration? Are state laws waived or modified? Does the declaration affect licensing requirements or liability protections?

What state or local licensing, credentialing, and scope of practice requirements apply to different health care providers, employees vs volunteers, or responders who travel across state lines or provide care in a different setting from the usual?

What state or local liability protections apply to employees vs volunteers or responders who travel across state lines?

Does the state participate in the EMAC? Has the state adopted the UEVHPA? What are the consequences of participation in that compact or state law?

Who orders evacuation of populations and areas, restrictions on access to affected areas?

Who orders seizure, destruction, or decontamination of property?

What opportunities exist for acquisition of property and supplies?

What is the standard of care for the state or local area? Is there a formal trigger or guidance for crisis standards of care?

What state or local requirements provide for informed consent by patients? Are there emergency exceptions?

What privacy protections apply to patient care? Are there emergency exceptions?

What reimbursement is available for patient care and other response activities?

What occupational safety standards, worker compensation, and employee benefits apply?

CHIP=Children's Health Insurance Program; DHHS=Department of Health and Human Services; EMAC=Emergency Management Assistance Compact; EMTALA=Emergency Medical Treatment and Active Labor Act; HIPAA=Health Insurance Portability and Accountability Act; PREP=Public Readiness and Emergency Preparedness; UEVHPA=Uniform Emergency Volunteer Health Practitioner's Act. 
der similar circumstances. Thus, the standard of care in responding to a nuclear detonation may be determined by the circumstances of the event itself, the resources and opportunities available to the responders, and the medical or crisis standards that a reasonable practitioner would use in the state.

Providers also have concerns about which liability protections apply if they respond to an emergency involving a nuclear detonation. The source and extent of liability protections may change when health care providers and other emergency responders provide care in different settings or under circumstances different from their norm, such as in a volunteer capacity, or in a different state. In response to a nuclear detonation, many responders may volunteer, or travel to the emergency area to respond. Under these circumstances, liability protections that typically apply to their regular employment may not be available or may vary from what is available in their home state. In such cases, a variety of liability protections at the state level may exist for employees and volunteers. ${ }^{17}$ In general, states have liability protections for state employees under tort liability acts. ${ }^{10}$ Mutual aid compacts, such as the Emergency Management Assistance Compact (EMAC), may offer liability protection for state officers and employees when 1 state requests assistance from another. ${ }^{10,17,18}$ Likewise, state governors may be able to extend liability protections under state law through emergency powers, generally following a declaration of an emergency, a public health emergency, a disaster, or a similar event. ${ }^{10,17}$ State emergency management statutes, Good Samaritan statutes, and state volunteer protection acts may also provide protections. ${ }^{10,17}$ The application of these protections varies depending on the circumstances, such as whether the provider is a state officer or volunteer, whether volunteer services are compensated, or where the care is provided. ${ }^{10,17}$ Thus, there is no comprehensive scheme for liability protection under these circumstances. ${ }^{10,17}$ Liability protections available to each responder and each event need to be examined. Furthermore, liability protections for entities or organizations are generally more limited or absent under these authorities. ${ }^{10,19}$

Some federal liability protections may also be available for federal, state, local, and private responders, including volunteers. Federal employees, including intermittent federal employees in the National Disaster Medical System or other federalized teams, are protected under the Federal Tort Claims Act when acting within the scope of their official duties. ${ }^{20}$ Volunteers may be protected by the federal Volunteer Protection Act. ${ }^{10,21}$ In addition, the Secretary of the Department of Health and Human Services (DHHS) has issued a declaration under the Public Readiness and Emergency Preparedness (PREP) Act to provide liability immunity for "covered persons" involved in the administration and use of acute radiation countermeasures. Covered persons include the United States, manufacturers, distributors, health care planners (including states, localities, tribes, private sector partners and others), and individuals who are qualified to administer countermeasures either under the law of their state or as identified by the Secretary in the declaration. ${ }^{22}$ How- ever, liability immunity under the PREP Act is available only under the terms of the declaration and the underlying statutory authority, and only for the administration and use of the radiation countermeasures covered by the declaration. Because the PREP Act applies only to administration and use of medical countermeasures, liability immunity is not afforded under the act for administration of general medical or palliative care that may be rendered in the event of a nuclear detonation. Other liability protections discussed in this section are not limited to administration and use of medical countermeasures. $^{23}$

Some of the liability protections discussed above provide immunity and some provide for indemnification. Immunity is an exemption from a legal obligation, whereas indemnification is like insurance. ${ }^{24}$ In general, liability protections for immunity would not cover legal fees, and legal expenses incurred in defending or seeking dismissal of a claim may need to be considered separately. Liability protections that provide indemnification may cover such costs, depending on the coverage..$^{10}$ In addition, both types of liability protections typically would not address the negative effects of claims on a provider's malpractice insurance.

\section{Licensing, Credentialing, and Scope of Practice of Health Care Providers}

Licensing, credentialing, and scope of practice requirements are also raised as concerns when responders contemplate responding to mass casualties after an emergency involving a nuclear detonation, particularly when there may be insufficient numbers of personnel or personnel with a particular area of expertise available to respond. A variety of arrangements may be in place, generally at the state and local levels.

Recognition of licensing and credentialing is an issue when health care providers and first responders travel across state lines in a regional response to a nuclear detonation. Licensing to practice health care professions is a matter of state law. ${ }^{1}$ Emergency medical services and ambulances may be regulated by local law. ${ }^{2}$ Credentialing of health care providers varies by profession. State officers and employees and volunteers may be able to practice when crossing state lines under mutual aid compacts, such as EMAC, but states may not be able to exchange private health care providers under these compacts unless the state recognizes these providers as state employees. ${ }^{5}$ States may also be able to recognize out-of-state licenses and other credentials, waive licensing requirements, or grant temporary licenses or credentials under their emergency laws, but this varies from state to state. ${ }^{5}$ Uniform model legislation, such as the Uniform Emergency Volunteer Health Practitioners Act recognizes public and private out-of-state health care professionals' licenses or other credentials in states that have declared emergencies, but the model legislation requires the providers to register in an advance registration system such as the Emergency System for Advanced Registration of Volunteer Health Professionals or the Medical Reserve Corps. ${ }^{25}$ Health care pro- 
viders who are federal employees and who are licensed in a state, as required by the terms of federal employment, may practice health care as their official duties in any state. ${ }^{26}$

Access to information about licensing and credentialing is also an issue in an emergency. The DHHS's Emergency System for Advanced Registration of Volunteer Health Professionals ${ }^{27}$ provides a state-based system for advance registration of health professionals to verify credentials, licenses, accreditations, and hospital privileges when such professionals volunteer to provide services during emergencies. The Medical Reserve Corps provides similar registration of volunteers at the local level..$^{28}$ The DHHS's National Practitioner Data Bank provides an alert system to facilitate a comprehensive review of health care practitioners' professional credentials. ${ }^{29}$ The National Practitioner Data Bank collects and disseminates information on medical malpractice payments, adverse licensing, clinical privileging, and professional society membership actions, and exclusions from Medicare and Medicaid to eligible entities.

Health care providers and responders also need to consider legal requirements related to scope of practice when responding to an emergency because professionals may need to function outside the legal scope of practice or level of training and supervision in an austere setting created by a nuclear detonation. ${ }^{30}$ During emergencies, state governments may change scope of practice requirements in a variety of ways. ${ }^{31}$ For example, the authority to prescribe medications is a matter of state law and can vary from state to state. States may use emergency authorities to suspend, modify, or expand prescription requirements to allow for greater distribution of radiation countermeasures or other drugs. ${ }^{31}$ The ability to handle controlled substances requires a license from the federal Drug Enforcement Administration $^{32}$ and may also require a state license.

\section{Legal Protections for Patients}

Patients' legal protections also must be considered when providing treatment after a nuclear detonation. Standards, exceptions, or waivers pertaining to these protections may be available to facilitate the provision of mass care after a nuclear detonation. For example, in a nuclear detonation in which resources are scarce, frameworks for allocation of care may be altered. In this environment, allegations of various forms of unlawful discrimination (based on, for example, race, sex, disability, or age) may be raised, as well as concerns about meeting treatment needs of at risk populations. ${ }^{3,33}$ Clear guidance about the allocation of resources for providers to use in making treatment decisions based on medical and public health priorities for treating individuals harmed in a nuclear detonation may help to address concerns that treatment decisions were driven by perceptions about race, sex, disability, or age.

Issues of patient informed consent and capacity to consent may also arise. In a nuclear detonation, many individuals may be seriously injured and physically or legally incapable of providing consent. Legal capacity to consent is, in general, a matter of state law. Most states have exceptions for providing emergency care to patients who are unable to consent because of physical injury or incapacity, age, or mental incapacity. State and local consent standards may also offer exceptions or waivers in emergencies. ${ }^{34}$ Availability of minimum or emergency standards for documentation of consent and for health care should also be reviewed, including how to handle these issues in alternate care settings that would likely be established after a nuclear incident. Consent to participate in medical research and use of data for medical research may also raise issues. Federal regulations governing human subjects research and local requirements should be considered when conducting medical research on patient care rendered during or after a nuclear detonation. $^{35,36}$

Federal and state laws address patient privacy, sharing of health care information with other entities, record keeping, and patient access to records. The federal Health Insurance Portability and Accountability Act (HIPAA) and the HIPAA Privacy Rule ${ }^{37}$ set standards for safeguarding the privacy of certain types of individually identifiable health information by entities covered by HIPAA. HIPPA allows use and disclosure of individually identifiable health information without patient consent in circumstances that may be relevant to emergency response, including, for example, as necessary to provide treatment or seek payment for services; with anyone the entity believes is reasonably able to prevent or lessen a serious and imminent threat to the health and safety of a person or the public; and to a public health authority acting as authorized by law in response to a public health emergency. ${ }^{37}$ Sanctions for noncompliance with certain HIPAA provisions may be waived temporarily when the President has declared a state of emergency or major disaster under the Stafford Act or National Emergencies Act and the DHHS Secretary has declared a public health emergency under the Public Health Service Act. This may include, for example, the need to distribute a notice of privacy policies or to obtain a patient's agreement before speaking with family members or friends. ${ }^{38}$ State laws for patient privacy may provide similar flexibility.

Finally, various mechanisms may exist for patients to be compensated for injuries related to the provision of medical care in a nuclear detonation. For example, under the PREP Act, a compensation fund may be made available for individuals who are injured as a consequence of administration or use of the medical countermeasures covered by the PREP Act declaration for acute radiation countermeasures. ${ }^{39}$ Individual compensation may also be available under the Stafford Act. ${ }^{40}$ Reimbursement for provision of other medical care may be available through other public or private insurance or other mechanisms.

\section{Legal Protections for Providers}

Responder safety needs also must be addressed to ensure an effective response to an emergency involving a nuclear detonation. Responders in and entering the area may incur their own health risks from exposure to radiation or other conditions in 
the area. Thus, legal requirements for occupational safety and worker protection requirements for responders need to be considered. Both federal and state laws and regulations provide worker safety requirements for health care providers and first responders working in a hazardous environment. Requirements include standards for exposure to radiation at levels that could remain in an area after a nuclear detonation and use of personal protective equipment to protect against radiation exposure. ${ }^{41}$ In addition, programs may be established for tracking responder exposure. ${ }^{42}$

Federal $^{43}$ and state laws also provide workers compensation protections for workers injured or killed in the scope of employment. ${ }^{44}$ At the state level, workers compensation systems may not cover volunteers, although many states extend workers compensation coverage to emergency volunteers through emergency management statutes or other means. For example, EMAC requires states that send emergency workers to another state to provide workers compensation coverage for those individuals. Other state statutes, such as the Uniform Emergency Volunteer Health Practitioners Act, where it has been adopted, may clarify which state is responsible for paying workers compensation when health care providers cross state lines. In addition, leave and pay benefits for responders who volunteer must be addressed and the protection of employment rights with the responder's primary employer. The Uniform Services Employment and Reemployment Rights Act ${ }^{45}$ protects some federal intermittent employees from job loss when they respond to emergencies as part of the federal response.

\section{Legal Issues Relating to Medical Supplies and Property}

Supplies and facilities must be available for a provider to respond to an emergency involving a nuclear detonation. In such an emergency, medical and other supplies may be scarce and facilities may be unusable. Legal issues can arise in procuring, distributing, and dispensing medical countermeasures and supplies. DHHS maintains the Strategic National Stockpile of drugs, vaccines, medical devices, and other supplies to provide for the emergency health security of the United States, including countermeasures that may be used to respond to a nuclear detonation. The Strategic National Stockpile may be deployed to respond to an actual or potential public health or other emergency, or as necessary to protect public health and safety. ${ }^{46}$ States and localities and the private sector may maintain similar stockpiles. The Nuclear Regulatory Commission, in partnership with DHHS, provides states with countermeasures for radiation. Eligible states are those with approved distribution plans and with populations within the 10 -mi radius surrounding nuclear power plants, referred to as emergency planning zone areas. ${ }^{47}$ The US Food and Drug Administration's approval of certain medical countermeasures and supplies may also need to be considered because countermeasures and supplies are shipped by interstate commerce. At the federal level, the federal Food, Drug, and Cosmetic Act authorizes DHHS to approve emergency use of unapproved products, or products approved for another use after a declaration of an emergency justifying such use, including countermeasures against radiological attacks. ${ }^{48,49}$

Even with the availability of stockpiles, immediately after a nuclear detonation, countermeasures and other supplies and facilities for treating patients may be scarce. When there is a need to obtain and distribute supplies and deliver health services quickly, questions of property acquisition and commandeering may arise. At the federal level, eminent domain has certain constitutional, statutory, and administrative restrictions and requires payment of just compensation to the owner of the property. ${ }^{50}$ There are also federal emergency procurement authorities, including the Defense Production Act, ${ }^{51}$ through which federal agencies can require priority performance or acceptance of contracts necessary to promote the national defense, including production of medical countermeasures and supplies. States and localities may also have the authority to commandeer property and exercise emergency procurement authorities. ${ }^{52}$ Surge capacity of health care facilities may be enhanced by flexibilities in Medicare, Medicaid, and Children's Health Insurance Program (CHIP) requirements.

Legal issues also arise in environmental decontamination of property to protect the public health. Authorities under the Comprehensive Environmental Response, Compensation, and Liability Act, the Resource Conservation and Recovery Act, and the Clean Water Act may be used by the federal government to control and clean up environmental contamination from a nuclear detonation, and to support state and local response. ${ }^{53}$ Legal authorities related to seizure, condemnation, or destruction of contaminated property, or other restrictions to prevent dispersion of contamination also may be used. States may be able to seize or destroy contaminated or dangerous property, with or without compensation, relying on state police powers and authorities to abate a nuisance. ${ }^{52}$ States may also be able to isolate or quarantine infectious individuals who can spread a disease or condition to others in the area, potentially including radiation contamination, or issue a curfew. ${ }^{52}$ Local jurisdictions may have separate quarantine and communicable disease control authorities. ${ }^{2}$ Using federal authorities for quarantine,${ }^{54}$ DHHS may order the destruction of contaminated articles to prevent interstate spread of disease in the event of inadequate local control. This authority also could be used, for example, to destroy personal articles of individuals that are contaminated by radiation.

Federal, state, and local jurisdictions may also be able to protect or restrict access to property or geographic areas under law enforcement authorities. States and local jurisdictions may be able to exercise police powers or emergency powers to force evacuation of the area or nearby areas, or close or order the evacuation of facilities. ${ }^{52,55}$ Municipal building codes and other property standards may need to be assessed when setting up temporary or emergency treatment facilities and in assessing decontamination of structures. ${ }^{2}$ 


\section{Reimbursement}

Reimbursement must be available to facilitate an initial and ongoing response to an emergency involving a nuclear detonation. States, health care providers, and responders may have concerns about reimbursement for care rendered in response to the emergency. Reimbursement may be provided to federal agencies, states, and individuals for certain actions when the President has declared a state of emergency or a major disaster under the Stafford Act. ${ }^{56}$ Reimbursement may also be available under the Price Anderson Act, if the emergency involves a release from a nuclear reactor. ${ }^{57}$ States that provide mutual assistance under agreements such as EMAC may also be able to obtain reimbursement from the receiving state, as provided under the agreement. Reimbursement may be available to hospitals, nursing homes, and other health care provider organizations that participate in Medicare, Medicaid, and the CHIP, even when normal conditions for these programs cannot be met. After an emergency such as a nuclear detonation, DHHS may be able to offer flexibility to providers in regard to meeting conditions of Medicare, Medicaid, and CHIP programs on a caseby-case basis. Such flexibility may be offered to health care providers both within and outside the emergency area as needed to respond to a detonation, including allowing for reimbursement of patients evacuated from the emergency area. ${ }^{58}$ Reimbursement also may be available through the National Disaster Medical System for participating hospitals that provide definitive patient care to victims of a nuclear detonation. ${ }^{59}$

If the President has declared a state of emergency or disaster under the Stafford Act or National Emergencies Act ${ }^{60}$ and the Secretary of DHHS has also declared a public health emergency, ${ }^{61} \mathrm{DHHS}$ also may waive or modify, on a case-by-case basis, certain conditions of participation for Medicare, Medicaid, and CHIP. ${ }^{7}$ Waivers are available for providers in the geographic area covered by the declarations. ${ }^{62}$ The purpose of the provision is to ensure the availability of health care items and services in an emergency for populations covered by these programs. ${ }^{7,62}$ Providers outside the area defined in the declarations are not eligible for waivers even if they receive patients from the emergency area. The waiver authority allows providers, who in good faith, are unable to comply with the conditions to be reimbursed and exempted from sanctions., ${ }^{7,62}$ One particular waiver that may be of use to health care facilities responding to a nuclear detonation is the ability to waive sanctions under the Emergency Medical Treatment and Active Labor Act (EMTALA). ${ }^{63}$ A health care facility that has an EMTALA waiver may redirect an individual to another location to receive a medical screening examination pursuant to a state emergency preparedness plan or may transfer an individual who has not been stabilized when the transfer arises from the emergency. A waiver of EMTALA after a detonation would be effective for 72 hours postimplementation of a hospital disaster protocol. ${ }^{7,62}$ Waiver of EMTALA is only effective if actions taken under the waiver do not discriminate on the basis of a patient's source of payment or ability to pay. ${ }^{7}$ Another waiver that may be useful in response to a nuclear detonation is a waiver of bed limits on critical-access hospitals. ${ }^{62}$

Reimbursement may also serve as a mechanism for the federal government to influence planning for emergencies such as a nuclear detonation. For example, DHHS and the Department of Homeland Security provide funding to states for public health emergency preparedness through grant programs. ${ }^{64} \mathrm{DHHS}$ also requires health facilities that participate in Medicare and Medicaid, including hospitals, nursing facilities, hospices, and criticalaccess hospitals, to plan for disasters, mass casualties, and evacuations. ${ }^{65}$

\section{CONCLUSIONS}

A variety of legal issues can arise at the federal, state, and local levels in response to a nuclear detonation. Authorities at each of these levels and how these authorities apply to a response must be examined and understood by jurisdictions in advance of a major emergency. Issues may be identified through planning and exercises, or may come to light during an emergency response. The precise authorities and procedures for invoking them need to be identified. In some cases, a lack of authority or process or an authority or process that creates a barrier to response may be identified. In such instances, new legislation or changes in regulations or ordinances may be a solution, or there could be changes in policy, procedures, guidance, or development of new standards. In other cases, the laws may be sufficient but poorly understood. In those instances, additional education and training in these authorities may be needed for government officials, emergency managers, responders and others. Perceptions about the law, levels of understanding, and resulting behavior also merit examination. In many instances, the perception of a law and consequent effect on response is not fully known. Understanding whether a law enables or inhibits responders and how emergency managers perceive and carry out their authorities would complement a review of legal authorities. Gaining this advance understanding of the legal issues, how laws are applied, what may need to be changed, what needs to be understood, and how laws are perceived and carried out can help jurisdictions prepare a more effective response to a public health emergency involving a nuclear attack.

Author Affiliation: Ms Sherman is with the Office of the General Counsel, US Department of Health and Human Services.

Correspondence: Address correspondence and reprint requests to Susan E. Sherman, Office of the General Counsel, US Department of Health and Human Services, 200 Independence Ave SW, Room 7A22, Washington, DC 20201 (e-mail: Susan.Sherman@hhs.gov).

Received for publication September 20, 2010; accepted January 20, 2011. This article was corrected on March 25, 2011.

The US Department of Health and Human Services (DHHS) provided funding to support this publication and convene the authors. The contents of the articles represent the personal views of the individual authors and do not necessarily express the opinion or policy of DHHS or its components. No statement in the articles should be construed as an official position of DHHS or its components.

Author Disclosures: The author reports no conflicts of interest. 
Acknowledgments: The author acknowledges the contributions and comments of colleagues from the Office of the General Counsel, US Department of Health and Human Services, Jennifer Garver, James Misrahi, and Jennifer Ray.

\section{REFERENCES}

1. Gostin L, Koplan J, Grad F. The law and the public's health: the foundations. In: Goodman RA, Hoffman RE, Lopez W, Matthews GW, Rothstein MA, Foster KL, eds. Law in Public Health Practice. New York: Oxford University Press; 2003:3-22.

2. McCarty KL, Nelson GD, Hodge J Jr, Gebbie KM. Major components and themes of local public health laws in select U.S. jurisdictions. Public Health Rep. 2009;124(3):458-462.

3. Hodge JG Jr, Garcia AM, Anderson ED, Kaufman T. Emergency legal preparedness for hospitals and health care personnel. Disaster Med Public Health Prep. 2009;3(2)(Suppl):S37-S44.

4. Examples of federal authorities for emergency declarations include the Robert T. Stafford Disaster Relief and Emergency Assistance Act, 42, USC 5121, et seq (2002), and the Public Health Service Act, 42 USC § 247d. Section 319 (2002). For more information about federal public health emergency declarations, see http://publichealthemergency.hhs.gov/Preparedness /support/secauthority/Pages/default.aspx. Additional information about state and local declarations of emergency may be found by consulting individual state and local statutes and codes or Web sites. See, for example, General Laws of Massachusetts, chap 17, S. 2A, at http://www.mass.gov /legis/laws/mgl/17/17-2a.htm and model emergency declaration for Massachusetts cities and towns at http://www.mass.gov/Eeops/docs/mema/emd _advisory_committee/appendix_a/local_declaration_of_emergency/Local \%20Emergency\%20Declaration\%20Template.doc.

5. Hodge JG Jr. Assessing the legal environment concerning mass casualty event planning and response. In: Phillips SJ, Knebel AR, eds. Mass Medical Care With Scarce Resources: A Community Guide. AHRQ Publ No. 070001. Rockville, MD: Agency for Healthcare Research and Quality; 2007.

6. A declaration of a public health emergency by the Secretary of Health and Human Services under Public Health Service Act is 1 such example (42 USC § 247d). Section 319 (2002).

7. Ray J. Federal declaration of a public health emergency. Biosecur Bioterror. 2009;7(3):251-258.

8. Statutes governing regulation of select agents is one such example (Public Health Service Act (42 USC 262a). Section 351a (2002)).

9. Barnett DJ, Taylor HA, Hodge JG Jr, Links JM. Resource allocation on the frontlines of public health preparedness and response: report of a summit on legal and ethical issues. Public Health Rep. 2009;124(2):295-303.

10. Hoffman S, Goodman RA, Stier DD. Law, liability, and public health emergencies. Disaster Med Public Health Prep. 2009;3(2):117-125.

11. A survey of providers regarding joining the Medical Reserve Corps indicates that concerns about liability are a factor in deciding whether to volunteeer (Qureshi K, Gershon RM, Conde F. Factors that influence Medical Reserve Corps recruitment. Prehosp Disaster Med. 2008;23:s27-s34). Conversely, a survey of international humanitarian organizations indicates that liability concerns do not significantly impair their operations, although one-third acknowleged that legal claims had been made against them (Fisher D. Regulating the Helping Hand: improving legal preparedness for cross-border disaster medicine. Prehosp Disaster Med. 2010;25 (3):208-212.

12. Hodge JG Jr, Courtney B. Assessing the legal standard of care in public health emergencies. JAMA. 2010;303(4):361-362.

13. Institute of Medicine. Guidance for Establishing Crisis Standards of Care for Use in Disaster Situations: A Letter Report. http://www.iom.edu/Reports 12009/DisasterCareStandards.aspx. Published 2009. Accessed April 2, 2010.

14. Annas GJ. Standard of care--in sickness and in health and in emergencies. N Engl J Med. 2010;362(22):2126-2131.

15. Firth PG. Standard of care--in sickness and in health and in emergencies. N Engl J Med. 2010;363(14):1379-1380, author reply 1380.

16. Gostin LO, Hanfling D, Hodge JG Jr, Courtney B, Hick JL, Peterson CA. Standard of care--in sickness and in health and in emergencies. N Engl J Med. 2010;363(14):1378-1379, author reply 1380.
17. Hoffman S. Responders' responsibility: liability and immunity in public health emergencies. Georgetown Law J. 2008;96:1913-1969.

18. For more information about the Emergency Medical Assistance Compact, see http://www.emacweb.org.

19. As of the date of publication, 13 states have enacted the Uniform Emergency Volunteer Health Practitioners Act, which offers a provision to confer immunity from vicarious liability upon entities that deploy and use volunteer health practitioners.

20. Federal Tort Claims Act. 28 USC $\S 2671$ et seq (1948). For more information about the act, see http://www.usdoj.gov/civil/FTCA.htm.

21. Volunteer Protection Act. 42 USC $§ 14501$ (1997).

22. Office of the Secretary, Department of Health and Human Services. Declaration Under the Public Readiness and Emergency Preparedness Act. 73 Fed. Reg. 61866. http://edocket.access.gpo.gov/2008/e8-24735.htm.

23. Public Health Service Act. 42 USC $\S 247 d-6 d$ and 42 USC § 247d-6e. Sections 319F-3 and 319F-4 (2005). For more information about the PREP Act, see http://publichealthemergency.hhs.gov/preparedness/legal/prepact /pages/prepqa.aspx.

24. Black's Law Dictionary. 5th ed. St Paul, MN: West Publishing; 1979.

25. For more information about the Uniform Emergency Volunteer Health Practitioners Act, see http://www.uevhpa.org.

26. This principle is set forth in a 1920 decision of the US Supreme Court, Johnson v Maryland, 254 US 51 (1920), based on the court's determination that the supremacy clause of the US Constitution indicates that state and local governments do not set the qualifications of federal employees.

27. Public Health Service Act. 42 USC § 247d-7b. Section 319I (2002). For more information about the Emergency System for Advance Registration of Volunteer Health Professionals, see http://www.phe.gov/esarvhp?Pages /deflautle.aspx.

28. Public Health Service Act. 42 USC $\S 300$ hh-15. Section 2813 (2006). For more information about the Medical Reserve Corps, see http://www .medicalreservecorps.gov/HomePage.

29. Health Care Quality Improvement Act. 42 USC $\S \S 11132-52$. Title IV (1986). For more information about the National Practitioner Data Bank, see http://www.npdb-hipdb.hrsa.gov.

30. Notably, in states that have adopted the Uniform Emergency Volunteer Health Practitioners Act, volunteer health practitioners would not be authorized to provide services that are outside the practitioner's scope of practice, even if a similarly licensed practitioner in the state was permitted to provide the service.

31. Courtney B, Morhard R, Bouri N, Cicero A. Expanding practitioner scopes of practice during public health emergencies: experiences from the 2009 H1N1 pandemic vaccination efforts. Biosecur Bioterror. 2010;8(3):223. 231.

32. Controlled Substances Act. 21 USC §§ 821-31 (1970).

33. Hoffman S. Preparing for disaster: protecting the most vulnerable in emergencies. UC Davis Law Rev. 2009;42:1491.

34. Hartman KM, Liang BA. Exceptions to informed consent in emergency medicine. Hosp Phys. 1999;35:53-59.

35. Public Health Service Act. 42 USC § 289. Section 491 (1985) 45 CFR Part 46 (1982). For more information about human subjects protection, see http://www.hhs.gov/ohrp.

36. For example, use of any products under an emergency use authorization does not meet the Food and Drug Administration's standards for clinical investigation; see the Food, Drug and Cosmetic Act. 21 USC §360bbb-3(k). Section 564 (2004).

37. Health Insurance Portability and Accountability Act, Pub L No. 104-191 (1996), 45 CFR Parts 160, 164 (1996).

38. Social Security Act. 42 USC 1320-5(b). Section 1136(b) (2005). For more information about Health Insurance Portability and Accountability Act waivers during an emergency, see http://www.hhs.gov/ocr/privacy/hipaa /faq/disclosures_in_emergency_situations/1068.html.

39. Public Health Service Act. 42 USC 247d-6e. Section 319F-4 (2005). For more information about the Countermeasures Injury Compensation Program, see http://www.hrsa.gov/gethealthcare/conditions/countermeasurescomp. 
40. Federal Emergency Management Agency. What is disaster assistance? http: //www.fema.gov/assistance/process/individual_assistance.shtm. Accessed February 7, 2011.

41. For more information on occupational safety standards, see http://www .osha.gov/SLTC/radiationionizing.

42. SAFE Port Act. 42 USC $\S 300 \mathrm{hh}-14$ (2006).

43. The Federal Employee Compensation Act provides workers compensation for federal employees, including intermittent employees of the $\mathrm{Na}$ tional Disaster Medical System, 5 USC § 8101, et seq (1966). For more information about the Federal Employee Compensation Act, see http: //www.dol.gov/compliance/laws/comp-feca.htm.

44. Sengupta I, Reno V, Burton JF Jr. Worker's compensation: benefits, coverage, and costs, 2005. http://www.nasi.org/research/2007/report-workers -compensation-benefits-coverage-costs-2005. Published August 2007. Accessed February 7, 2011.

45. Uniformed Services Employment and Reemployment Rights Act. 38 USC $4301 \S$ et seq (1994). For more information about the act, see http://www .dol.gov/compliance/laws/comp-userra.htm.

46. Public Health Service Act. 42 USC 247d-6b(a). Section 319F-2(a) (2004).

47. Nuclear Regulatory Commission. 10 CFR $\$ 50.47$ (b)(10) (2007). For more information about Nuclear Regulatory Commission distribution of potassium iodide, see http://www.nrc.gov/about-nrc/emerg-preparedness/protect -public/potassium-iodide.html.

48. Federal Food, Drug, and Cosmetic Act. 21 USC $\S 360$ bbb-3. Section 564 (2004). For more information about emergency use of medical countermeasures under Section 564 of the act, see guidance provided at http: //www.fda.gov/oc/guidance/emergencyuse.html.

49. Sherman SE, Foster J, Vaid S. Emergency use authority and 2009 H1N1 influenza. Biosecur Bioterror. 2009;7(3):245-250.

50. Jacobsen P, Hoffman RE. Regulating public health: Principles and applications of adminstrative law. In: Goodman RA, Hoffman RE, Lopez W, Matthews GW, Rothstein MA, Foster KL, eds. Law in Public Health Practice. New York: Oxford University Press; 2003:23-42.

51. Defense Production Act. 50 App USC § 2061 et seq (1950).

52. Misrahi J, Matthews GW, Hoffman RE. Legal authorities for interventions during public health emergencies. In: Goodman RA, Hoffman RE, Lopez W, Matthews GW, Rothstein MA, Foster KL, eds. Law in Public Health Practice. New York: Oxford University Press; 2003:195-210.

53. Comprehensive Environmental Response, Compensation, and Liability
Act. 42 USC $\S 9601$ et seq (1980). Resource Conservation and Recovery Act 42 USC $\S \S 6901-6992 k$ (1976). Clean Water Act 33 USC $\S \S 1251$ 1387 (1972).

54. Public Health Service Act. 42 USC $§ 264$, 265. Sections 361 and 362 (2002). For more information about federal quarantine, see http://www .cdc.gov/quarantine.

55. Wolshon B, Urbina E, Wilmot C, et al. Review of policies and practices for hurricane evacuation. I: Transportation planning, preparedness, and response. Nat Hazards Rev. 2005;6:129-142.

56. Robert T. Stafford Disaster Relief and Emergency Assistance Act. 42 USC $\S \S 5121-5206$ (2002).

57. Price Anderson Act. 42 USC § 2014(w) (1946).

58. For example, after Hurricane Katrina, the Department of Health and Human Services was able to assist affected health care providers in a variety of ways through Medicare, Medicaid, and the Children's Health Insurance Program. In addition, Congress specifically authorized and funded the Department of Health and Human Servicesto reimburse uncompensated care through the National Disaster Medical System and Medicaid. For more information about payments through these mechanisms, see http: //www.hhs.gov/disasters/emergency/naturaldisasters/hurricanes/katrina /fedpayment.html.

59. Public Health Service Act. 42 USC § 300hh-11. Section 2812 (2006). For more information about the National Disaster Medical System, see http: //www.phe.gov/Preparedness/responders/ndms/Pages/default.aspx.

60. National Emergencies Act. 50 USC $§ 1601$ et seq (1976).

61. Public Health Service Act. 42 USC § 247d. Section 319 (2002).

62. Social Security Act. 42 USC 1320b-5. Section 1135 (2006). For more information about 1135 waivers, see http://www.cms.hhs.gov /SurveyCertEmergPrep/Downloads/AllHazardsFAQs.pdf.

63. Social Security Act. 42 USC $\$ 1395 d d$. Section 1867 (2003).

64. Public Health Service Act. 42 USC $\$ \$ 247 d-3 a, 247 d-3 b$. Sections 319C-1 and 319C-2 (2006). For more information about federal grants from the Departments of Health and Human Services and Homeland Security, see http://www.hhs.gov/aspr/opeo/hpp, http://www.bt.cdc.gov/cotper /coopagreement, and http://www.dhs.gov/xgovt/grants/index.shtm.

65. Social Security Act. 42 USC $\S \S 1395 i-3(d)(4)(b), 1395 x(e)(9), 1395 x$ $(\mathrm{dd})(2)(\mathrm{g})$, and $1395 \mathrm{x}(\mathrm{a})(1)$ (2010). 42 CFR 418.110(b), 482.41(b)(7), 483.75(m)(1), 485.623(c)(4). Sections 1819(d)(4)(b), 1861(e)(9), 1861 $(\mathrm{dd})(2)(\mathrm{g}), 1871(\mathrm{a})(1)(2010)$. 